\title{
The Relationship Between Early Recruitment-Related Activities and the Application Decisions of New Labor-Market Entrants: A Brand Equity Approach to Recruitment
}

\author{
Christopher J. Collins \\ Cornell University
}

\author{
Cynthia Kay Stevens \\ University of Maryland
}

\begin{abstract}
Theory and research from the marketing literature on customer-based brand equity were used to predict
how positive exposure to 4 early recruitment-related activities-publicity, sponsorships, word-of-mouth endorsements, and advertising - may affect the application decisions of engineering students. Similar to prior marketing findings, the results suggested that early recruitment-related activities were indirectly related to intentions and decisions through 2 dimensions of employer brand image: general attitudes toward the company and perceived job attributes. The relationships between word-of-mouth endorsements and the 2 dimensions of brand image were particularly strong. In addition, it was found that early recruitment-related activities interacted with one another such that employer brand image was stronger when firms used publicity in conjunction with other early recruitment-related activities.
\end{abstract}

Sustained economic growth in the 1990s led to tight labor markets (U.S. Department of Labor, 2001) and increased the importance of recruitment in the competition for the technically skilled individuals necessary to fill knowledge-based jobs (Munk, 1998). Despite the subsequent economic downturn, recruitment remains a key tool for attracting those workers with rare and valuable skills (Barber, 1998), and for increasing the utility of selection systems (Boudreau \& Rynes, 1985). Moreover, census data indicate that demographic trends such as a smaller supply of younger workers and retirements among baby boomers will make it difficult to fill openings for the next decade (Dohm, 2000), particularly those requiring technical and engineering skills. Although researchers have responded to the need for sound recruitment advice, Breaugh and Starke (2000) suggested that we still lack solid understanding of how and why recruitment practices affect job seekers.

This research gap is particularly striking during what Barber (1998) identified as the initial phase of recruitment in which organizations seek to attract prospective applicants. Yet this early phase is critical because a decision not to apply for an opening is

Christopher J. Collins, School of Industrial and Labor Relations, Cornell University; Cynthia Key Stevens, Robert H. Smith School of Business, University of Maryland.

We acknowledge with appreciation the financial support we received from Applied Materials, Lockheed Martin, and Raytheon, who sponsored our research. We also thank Susan Taylor for her insightful comments on drafts of this article, Dan Simon for his invaluable guidance on the data analyses and Jim Breaugh for comments and suggestions that greatly improved the article.

Correspondence concerning this article should be addressed to Christopher J. Collins, School of Industrial and Labor Relations, 387 Ives Hall, Cornell University, Ithaca, New York 14853-3901. E-mail: cjc53@ cornell .edu tantamount to a rejection decision. Although previous research has provided some insight, several issues require further investigation. First, previous recruitment studies have lacked solid theoretical grounding resulting in a misrepresentation of the complexity of the recruitment process (Breaugh \& Starke, 2000; Rynes, 1991). Therefore, recruitment researchers need to develop stronger theories and examine more sophisticated relationships that specify mediated variables. Second, although organizations may use multiple recruitment practices simultaneously, the effects of such practices have often been studied in isolation (Rynes, 1991); thus, we have little knowledge regarding how various recruitment practices interact with each other. Moreover, researchers have tended to examine a narrow range of practices, even though there are a variety of human resource practices and other organizational activities that may attract potential applicants (Barber, 1998). Finally, between-subjects designs, which have been used in most field studies on recruitment, fail to capture the complexity involved when decision makers evaluate multiple job options (Olian, 1986). Thus, recruitment researchers should consider using other techniques that more appropriately assess the effects of recruitment practices when respondents evaluate multiple options simultaneously.

To develop an understanding of how organizational activities early in the recruitment process may affect job seekers' application decisions, we turned to marketing theory and research. Specifically, research on customer-based brand equity (Aaker, 1991; Keller, 1993) indicates that by creating a unique, favorable brand image in consumers' minds, organizations can increase the likelihood that their products or services will be chosen over similar products or services. Cable and Turban (2001) have argued that similar processes may affect job seekers' decisions during recruitment so that organizations with strong brand identities would be preferred to those with weak or negative brand identities. 
The purpose of this article is to use brand-equity concepts as a basis for exploring how organizational activities during the early recruitment phase may affect the application decisions of a highdemand labor market segment: New graduates from top engineering programs. Toward this end, we relied on theory and research findings from brand-equity literature to identify four sets of early recruitment-related activities-publicity, sponsorship, word-ofmouth endorsements, and advertising. We used brand-equity literature and findings from previous recruitment studies to make predictions about how positive exposure to these activities influences employer brand equity as perceived by potential applicants. Furthermore, we also considered the relative advantages of a within-subjects design when assessing the impact of early recruitment-related practices, which may be influential early in the process when job seekers consider applying to multiple organizations.

\section{Conceptual Background and Hypotheses}

Customer-based brand equity refers to beliefs held by individual consumers about a product's or a service's brand (i.e., perceptions of the name or logo) that affect their preferences and purchasing decisions relative to other unbranded products or services with similar attributes (Aaker, 1991, 1996; Keller, 1993). Such brand equity plays a critical role in consumers' decisions by (a) increasing the chances that the branded product or service will be among those considered when a purchase is imminent, (b) generating positive affect toward the branded product or service, and (c) creating points of differentiation and reasons to choose the brand over its competitors (Aaker, 1996; Keller, 1993).

As Cable and Turban (2001) proposed, the brand equity concept can be generalized to recruitment contexts in which job seekers confront issues similar to those faced by consumers. As consumers do with products and services, job seekers form beliefs about potential employers; these beliefs provide the basis for decisions about whether to pursue or accept employment offers (Barber, 1998). If such beliefs, which we call employer brand image, are similar in structure and impact to product brand images, then recruitment researchers may gain insight into the relative effectiveness of various recruitment practices by examining analogous dimensions of employer brand image and product brand image and the marketing activities known to affect those dimensions.

\section{Key Dimensions of Brand Image}

Brand image, which forms the basis for consumers' decisions, resides in the memories of individual consumers. As a result, marketing researchers have drawn on accepted models of associative memory (Anderson, 1983; Wyer \& Srull, 1989) to understand key dimensions. Such memory models postulate that information is stored in the form of nodes (specific bits of information) which are connected by links that vary in strength. When a node is recalled or activated, it triggers activation of other nodes according to the strength of the link, and this related information becomes available for use. Under this conceptualization, information about and memory of a product brand (and presumably an employer brand) have two key dimensions: (a) the node itself, or awareness of the brand or employer and (b) its links to related information, or the associated feelings and knowledge of the brand or employer (Keller, 1993). While awareness of the brand is important because it increases the likelihood and ease with which the brand can be brought to mind (Aaker, 1991), we were particularly interested in the associated feelings and knowledge about the brand (i.e., employer brand image). We controlled for individuals' awareness through the design of the study, because respondents evaluated only firms with which they were aware of as potential employers.

Once activated as part of a decision set, consumers use brand image to make comparisons and discriminate among similar products or services (Keller, 1993). Two aspects of image are important: (a) attitudes, or general affective responses associated with the brand (Wilke, 1986), and (b) perceived attributes or beliefs about the brand's specific features that are relevant to the purchase decision (Keller, 1993). Note that brand images reflect associations in memory based on exposure to advertising or to the brand itself and thus may not accurately reflect reality. Nonetheless, when consumers hold strongly favorable attitudes and perceive brands to have unique, desirable attributes, they are more likely to distinguish and purchase those brands over the brands of competitors (Aaker, 1996).

On the basis of the findings in the marketing literature, we expected that individuals' application decisions regarding firms in their decision set (i.e., those firms about which they are making application decisions) may be affected by employer brand image, which we define as potential applicants' attitudes and perceived attributes about the job or organization. Interestingly, recruitment researchers have provided definitions of organizational image that are similar to these two dimensions of brand image. For example, organizational image in the recruitment literature has been described as both general reactions toward a company (Gatewood, Gowan, \& Lautenschlager, 1993) and beliefs about a specific set of attributes about the firm (Belt \& Paolillo, 1982). Indeed, recruitment research has converged on both job seekers' attitudes (e.g., organizational attractiveness) and perceived job attributes as critical dimensions of job seekers' beliefs about employers (Barber, 1998; Rynes, 1991).

\section{Effects of the Marketing Mix on Brand Images}

As discussed above, there is a limited amount of research that examines how recruitment activities affect potential applicants during the initial phase of recruitment (Barber, 1998). However, we can draw on customer brand equity and marketing studies to identify several organizational activities that may affect employer brand image. Research indicates that an organization's marketing mix - the marketing activities used to sell a given product or service-increases customer-based brand equity because it raises awareness, generates favorable attitudes, and strengthens associations between the brand and desirable attributes (Aaker \& Biel, 1993). Moreover, such marketing activities may be particularly important for influencing inexperienced consumers who may be unsure of what attributes to seek or how to search for and evaluate product or service information. Heilman, Bowman and Wright (2000) found that such consumers rely heavily on marketing activities as signals of unknown, important attributes and as a basis for their brand attitudes. The definition of marketing mix above matches well with Barber's (1998) definition of recruitment that 
suggested that recruitment-related practices include the set of activities that affect the decision making of potential and actual applicants. Thus, to the extent that new labor market entrants are similar to inexperienced consumers, these findings suggest that the marketing mix inherent in organizational activities can have potent recruitment effects among such job seekers.

There is a broad array of practices that are considered to be part of a firm's marketing mix, including such wide ranging activities as advertising (Simon \& Sullivan, 1993), promotional events (Keller, 1993), price discounts and coupons (Aaker, 1996), public relations (Aaker, 1991), and warranties (Boulding \& Kirmani, 1993). However, not all of these activities match with recruitment activities (e.g., there is no recruitment counterpart to coupons). For the purposes of this article, we have focused on four major marketing activities that appear to be similar to current early recruitment activities: (a) publicity, (b) sponsorships, (c) personal or word-of-mouth endorsements, and (d) brand-specific product or service advertising. As each of these marketing activities corresponds to various recruitment activities, we discuss them and their effects on brand and employer knowledge separately below.

Publicity and brand images. Publicity, defined as information about a product or service communicated through editorial media that is not paid for by the organization (Cameron, 1994), represents a highly effective means of enhancing product brand image (Aaker, 1991). Although such publicity is not under direct organizational control, organizations can positively influence the publicity they receive through press releases and public relations campaigns (Cameron, 1994). Marketing literature suggests publicity influences brand images because consumers find it to be more credible (Schwarz, Kumpf, \& Bussman, 1986) and memorable (Cameron, 1994) than paid advertisements. Because the nature and frequency of publicity received depends on decisions made external to the organization, it does not consistently provide information about brand attributes (Hallahan, 1996). Thus, publicity is likely to influence consumers' attitudes but not their perceptions of specific attributes.

Consistent with this conceptualization, Barber (1998) suggested that media publicity about firms may have spillover effects on their recruitment efforts. Some data support the contention that publicity may affect employer brand image. For example, Turban and Greening (1997) found that among Fortune 500 firms, those rated higher in corporate social responsibility by an independent source had more media exposure and were more attractive potential employers to a sample of graduating students. As with marketing, publicity is not in the direct control of the staffing function of an organization; therefore, it is likely that publicity will only convey very general messages about a company and will only affect generalized perceptions of the firm. Thus, we expected that publicity (which communicates general information) would have greater effects on attitudes than on perceptions of job attributes.

Hypothesis 1: Exposure to greater levels of publicity about an organization will be more strongly related to job seekers' attitudes about the organization than it will to their perceptions of job attributes.

Sponsorship and brand images. As with publicity, corporate sponsorship activities have been used primarily to increase con- sumers' brand awareness (Aaker, 1996). More recently, however, research has shown that corporate sponsorships can improve both brand and corporate images by fostering positive affect among individuals who attend sponsored events or become aware of the sponsorship (Johar \& Pham, 1999). However, because sponsorship promotes generalized affective associations, it tends to have weak or nonsignificant effects on perceptions about specific brand attributes (Rajaretnam, 1994).

Following the trends in product marketing, many corporations have begun expanding their recruitment efforts to include sponsorships of campus activities to build employer brand image (Poe, 2000). For example, several telecommunications firms have donated money for scholarships and equipment to the Electrical and Computer Engineering Department at Virginia Tech (Behr, 1997), whereas other companies have sponsored tailgate parties at campus sporting events or concerts (Munk, 1998). Assuming that such activities have effects on brand images similar to those of event sponsorships, we predicted that sponsorship will have a greater impact on job seekers' attitudes than on their perceptions of job attributes.

Hypothesis 2: Exposure to organizational sponsorship activities will be more strongly related to job seekers' attitudes about the organization than to their perceptions of the job's attributes.

Word-of-mouth endorsements and brand images. Brand images can also be enhanced through word-of-mouth endorsements, which is a staple approach for affecting consumers' brand knowledge (Cobb-Walgren, Ruble, \& Donthu, 1995). Research suggests that consumers reduce the risks associated with their purchases by seeking information from credible sources, such as friends or people perceived to have relevant expertise (Cobb-Walgren et al., 1995). Such sources can provide both specific attribute information and more general attitudes about available brands. Word-ofmouth endorsements typically have the greatest impact on consumer decisions when they are positive and clearly distinguish among brands (Keller, 1993).

Recruitment research seems to suggest that word-of-mouth endorsements can have a similarly strong effect on employer brand image. For example, Fisher, Ilgen and Hoyer (1979) showed that graduating students found information obtained from people outside the organization to be more credible than the same information obtained from organizational representatives. Further, Fisher et al. found that students were most likely to accept job offers when exposed to positive information about the company. Similarly, Kilduff (1990) found that graduating MBA students showed strong preferences for organizations that were most preferred by their peers; these effects persisted after controlling for students' degrees and work experience.

As with publicity, organizations lack the ability to directly control word-of-mouth endorsements. However, it is possible to engage in recruitment activities that increase the chances that positive word-of-mouth endorsements will occur. For example, Coombs and Rosse (1992) and May (1998) have suggested that firms can attract graduating students by developing closer relationships with key individuals at targeted universities. Other strategies include offering summer research grants for faculty, using alumni 
as recruiters at their alma maters, and building relationships with career services staff. Thus, we predicted that positive word-ofmouth endorsements about a company have effects similar to those of brand endorsements, that is, individuals will have more positive general attitudes and perceptions of job attributes when they have been exposed to positive word-of-mouth endorsements.

Hypothesis 3: Greater exposure to positive word-of-mouth endorsements will be positively related to (a) job seekers' attitudes about the organization and (b) their perceptions of the opening's attributes.

Advertising and brand images. Advertising refers to paid, professionally designed messages, channeled through various media outlets, that are used to modify consumers' perceptions (Aaker, 1996). Because advertising is directly controlled by organizations, it can be crafted to create desirable brand-attribute associations in consumers' minds (Boulding, Lee, \& Staelin, 1994) as well as to foster positive attitudes toward the brand (Milgrom \& Roberts, 1986; Cobb-Walgren et al., 1995). Advertising can be particularly beneficial when consumers do not have direct experience with a brand or product class, because it provides specific information about attributes relevant to consumers' decisions and may result in positive attitudes toward the brand (Keller, 1993).

Recruitment advertising, in the form of brochures and job postings, has traditionally been used to disseminate information about openings (Rynes, 1991). Further, Barber (1998) noted that these job advertising sources are frequently used by job seekers when making application decisions. Although, there is limited research on early recruitment advertising, the findings of several studies suggest that such advertising has effects on employer brand equity that are similar to those observed in marketing. For example, Barber and Roehling (1993) found that exposure to recruitment brochures affects both specific beliefs and general attitudes toward job openings. Thus, we expected to replicate these findings when exploring a broader range of recruitment advertisements (e.g., Web sites, flyers, newspaper ads).

Hypothesis 4: Greater exposure to an organization's early recruitment advertising will be positively related to (a) job seekers' attitudes about the organization and (b) their perceptions of the opening's attributes.

Combined effects of marketing activities. Combined with uncertainty about the brand/employer, competing messages from other brands/employers, and limited resources with which to search for and evaluate information, the effects of exposure to a single marketing activity are likely to be limited (Aaker, 1996). Conceptually, exposure to multiple sources conveying information about the brand will strengthen the associations among nodes in memory (Wyer \& Srull, 1989). In addition, consumers (and perhaps job seekers) view multiple marketing activities as a positive signal of the presence of brand attributes, because consumers assume that firms only invest significant money on superior products (Keller, 1993). Consistent with this reasoning, we predicted interactive effects of early recruitment-related practices such that exposure to multiple recruitment practices will foster more posi- tive attitudes and job-attribute perceptions than will exposure to single practices.

Hypothesis 5: Exposure to more early recruitment-related activities (publicity, sponsorships, word-of-mouth endorsements, and recruitment advertising) experienced during job search will foster more positive organizational attitudes and more positive perceptions of job attributes among job seekers than will exposure to single early recruitment-related activities.

\section{Brand Images and Decision Making}

The impact of branding is greatest in a crowded marketplace and among inexperienced consumers because these circumstances make it difficult to cognitively compare available products or services based on key attributes (Aaker, 1996; Cobb-Walgren et al., 1995). Instead, consumers use their perceptions of brand image to evaluate available brands against their needs and select those that provide the best match (Aaker, 1991; Keller, 1993). Recruitment literature suggests that many parallels exist between this conceptualization of brand image and the situation faced by new labor market entrants. For inexperienced job seekers, it is difficult to compare the available options on the basis of the true attributes of the job and company because many attributes are unknown or unknowable. Thus, job seekers may rely on employer brand images for guidance in decision making. As with the product branding process, organizations may indirectly influence potential applicants' decisions through the effect of their recruitment mix on employer brand images (i.e., attitudes and perceived attributes). Accordingly, we predicted that job seekers' employer brand images would mediate the impact of organizational recruitment activities on job seekers' intentions and decisions.

Hypothesis 6: The relationship between exposure to early recruitment-related practices and job seekers' application intentions and decisions will be mediated by the two dimensions of employer brand image (attitudes and perceived job attributes).

\section{Methodological Issues}

Most prior field studies of recruitment practices have examined their impact using between-subjects designs, that is, by correlating job seekers' perceptions of a single firm's practices with their reactions to that firm. Although these designs yield useful insights, they are not optimal for studying recruitment practice effects. By asking job seekers to consider one firm, the between-subjects approach fails to capture the larger context in which multiple options are considered. Hsee, Loewenstein, Blount, and Bazerman (1999) noted that when decision makers have difficulty evaluating the desirability of option attributes, they often exhibit preference reversals if they consider the same options one at a time versus simultaneously. Thus, between-subjects designs may misspecify recruitment effects by restricting how options are evaluated. A second issue is that between subjects designs do not permit researchers to remove the effects of individual differences that may prevent detection of smaller effects. Finally, firms may vary in the 
number and types of recruitment practices deployed. Restricting the stimulus set to a single organization may inadequately sample the range of practices to which respondents are exposed, thereby restricting the range in predictor variance.

Olian (1986) suggested that within-subjects designs are optimal when researchers wish to evaluate decision making that involves simultaneous evaluation of multiple options. Within-subjects designs in this case would involve collecting data on job seekers' exposure to recruitment-related practices across multiple firms and job seekers' reactions to each of those firms. Used in conjunction with fixed-effects regression analyses (Greene, 1997), withinsubjects designs permit researchers to sample a wide range of practices and to remove individual differences from their error terms; therefore, we combined both procedures for this study.

The data reported below were collected as part of a longitudinal study examining the impact of recruiting practices on the job choices of engineering students. To obtain a broadly representative sample, we solicited and obtained the participation of three top engineering schools (as rated in 1997 by U.S. News and World Report; Koerner, 1987) from different geographic regions during tight labor market conditions in 1998-1999. The national unemployment rate in 1998 was $4.5 \%$, although some writers (e.g., Munk, 1998) suggested that the rate for college graduates with up-to-date technical skills was near zero. Hence, the nature of the labor market for our sample, and feedback from career services personnel, suggested that most of our respondents would feel that they had multiple openings from which to choose.

\section{Method}

\section{Sample and Procedures}

The career services offices at three engineering schools provided us with a list of the names and addresses of graduating students who had registered for placement services. We sent cover letters, surveys, and a supporting letter written by the local career services director to each of these students $(n=1,955)$. As an incentive for participation, we offered students the chance to win cash prizes in lottery drawings for each school. We also provided self-addressed stamped envelopes so that surveys could be returned directly to us, thereby ensuring confidentiality. Of those surveys mailed, approximately $10 \%$ to $13 \%$ were returned because of incorrect mailing addresses (often for students who had previously graduated). Our final sample consisted of 133 students who were graduating with bachelor's or master's degrees in engineering. Nearly $70 \%$ of the respondents were men, although the sample was ethnically diverse (65\% White, $24 \%$ Asian, 5\% African American, and 6\% other) with an average grade point average (GPA) of 3.24. We found that over $70 \%$ of our sample had less than 1 year of work experience, which suggests that we were successful in finding a sample of relatively inexperienced job seekers.

Given the incomplete information available through the career services offices, it was difficult to estimate the response rate precisely. Thus, we examined sample representativeness by comparing our respondents to the survey population. Available demographic data on the graduating student populations at two of the three engineering schools indicated that our sample did not differ significantly from the graduating population in gender, $\chi^{2}(1, N=1,230)=0.22, n s$; GPA, $t(133)=1.57, n s$; or years of experience, $t(133)=1.22, n s$. Thus, there is evidence that response rate bias in our sample may not be a problem.

Initial surveys were distributed to students during the first two weeks of the semester, approximately 1 month before they could apply (i.e., register) for company interviews through their respective career services offices. In collecting information, we used a within-subjects design in which respondents listed up to 10 organizations in which they had some interest. For each organization listed, respondents described the early recruitmentrelated practices to which they had been exposed as well as their attitudes about each employer, perceptions of opening's attributes, and intentions to pursue employment. A follow-up survey sent 2 months later listed the organizations from the first survey and asked respondents to indicate those to which they had actually applied.

\section{Measures of Early Recruitment-Related Practices}

Where possible, we assessed variables using established, reliable measures. However, most of the early recruitment-related practices we targeted have not been studied so we had to generate new indices. To do this, we first examined the practitioner and research literatures to identify examples of early recruitment-related practices consistent with activities from marketing literature. We then discussed with several career services directors and staffing managers how these activities might be perceived by graduating students. (For example, students might not know that a given firm was attempting to foster word-of-mouth endorsements through relationship building, but they might know that faculty or career services personnel held favorable opinions of that firm.) Based on these discussions and literatures, we generated 14 items that were consistent with the four practices in the marketing literature and relevant to students' recruiting experiences. Respondents rated each item on a scale ranging from 1 (strongly disagree) to 5 (strongly agree).

Item analyses. The preliminary principal components analysis indicated that one item ("My friends think that this would be a great organization to work for") split equally across two components. Because that particular item could not cleanly differentiate components, we dropped it from further consideration. The second principal components analysis with varimax rotation on the remaining 13 items yielded four components with eigenvalues greater than 1.0 (61\% of item variance explained; see Table 1). All items loaded on components consistent with our a priori expectations. Reliability analyses indicated reasonable item convergence: publicity $\alpha=$ .75; sponsorship activities $\alpha=.70$; word-of-mouth endorsements $\alpha=.76$; and recruitment advertising $\alpha=.78$. We formed composites by averaging the ratings for items associated with each practice.

Preliminary validity data. One concern about field studies of recruitment is the extent to which the measures actually reflect respondents exposure to recruitment-related practices or something else (e.g., preconceptions about what practices would be used or generalized response bias) To determine the validity of the current measures, we used two approaches. First, we examined convergence in different respondents' ratings of the same recruitment-related practices used by the same organizations. To do this, we calculated the interclass correlation (ICC; both ICC [1] and ICC [2] as suggested by Bliese, 1998) for 46 organizations rated by five or more respondents. Analyses indicated that multiple respondents showed greater agreement on their exposure to practices from the same organization than individual respondents did on their exposure to practices from different organizations (publicity ICC $[1]=.210, \mathrm{ICC}[2]=.705$; sponsorships ICC $[1]=.243$, ICC $[2]=.743$; word-of-mouth endorsements ICC $[1]=$ .243 ICC[2] $=.743$; recruitment advertising $\mathrm{ICC}[1]=.286$, ICC $[2]=$ .783).

Second, we contacted the recruitment coordinators for organizations listed by five or more respondents and asked them to indicate (a) what engineering schools they had visited in the prior year, and (b) what recruitment-related practices they had used. Of the 46 firms contacted, 29 (63\%) responded. We did not include measures of publicity because we assumed that recruitment coordinators would have little direct control over these activities. However, nine items corresponding to those on the student survey yielded useable data. For each item, we aggregated students' responses about the organization's use of the practice and correlated this 
Table 1

Principal-Components Loadings for Early Recruitment Practice Measures

\begin{tabular}{|c|c|c|c|c|}
\hline \multirow[b]{2}{*}{ Measure and item } & \multicolumn{4}{|c|}{ Component } \\
\hline & 1 & 2 & 3 & 4 \\
\hline \multicolumn{5}{|l|}{ Publicity } \\
\hline $\begin{array}{l}\text { 1. Top officials from this organization (e.g., its CEO) } \\
\text { are often quoted in newspapers or trade journals. }\end{array}$ & .017 & .006 & .733 & .280 \\
\hline $\begin{array}{l}\text { 2. I have seen news stories about this organization } \\
\text { (e.g., TV or newspapers) }\end{array}$ & .203 & -.002 & .766 & .129 \\
\hline \multicolumn{5}{|l|}{ Sponsorship activities } \\
\hline $\begin{array}{l}\text { 3. I have worked on equipment or products donated } \\
\text { by this organization. }\end{array}$ & .663 & .018 & .224 & .016 \\
\hline $\begin{array}{l}\text { 4. This organization sponsors scholarships at my } \\
\text { university. }\end{array}$ & .829 & .042 & .009 & .012 \\
\hline $\begin{array}{l}\text { 5. This organization has sponsored events (e.g., } \\
\text { speakers, concerts, sports events) on campus. }\end{array}$ & .729 & .183 & .003 & .217 \\
\hline \multicolumn{5}{|l|}{ Word-of-mouth endorsements } \\
\hline $\begin{array}{l}\text { 6. A lot of alumni from this university go to work } \\
\text { for this organization. }\end{array}$ & .082 & .112 & .129 & .732 \\
\hline $\begin{array}{l}\text { 7. Students who have gone to work for this } \\
\text { organization have had good experiences. }\end{array}$ & .088 & .034 & .108 & .749 \\
\hline $\begin{array}{l}\text { 8. The engineering faculty think this organization is a } \\
\text { good place to go to work. }\end{array}$ & .010 & -.003 & .170 & .697 \\
\hline $\begin{array}{l}\text { 9. This organization has a good relationship with the } \\
\text { career services office. }\end{array}$ & .117 & .214 & .064 & .624 \\
\hline \multicolumn{5}{|l|}{ Advertising } \\
\hline $\begin{array}{l}\text { 10. I have seen advertising for jobs at this } \\
\text { organization in the school newspaper or on flyers. }\end{array}$ & .008 & .740 & -.034 & .122 \\
\hline $\begin{array}{l}\text { 11. Company recruitment brochures or Web site gave } \\
\text { me detailed information about their job } \\
\text { opportunities. }\end{array}$ & .004 & .699 & -.008 & .146 \\
\hline $\begin{array}{l}\text { 12. This organization's recruiting brochures caught my } \\
\text { attention. }\end{array}$ & .034 & .777 & -.044 & .008 \\
\hline $\begin{array}{l}\text { 13. Job postings gave me detailed information about } \\
\text { openings for which this organization is recruiting }\end{array}$ & .166 & .652 & .012 & .034 \\
\hline Eigenvalues & 2.273 & 1.849 & 1.693 & 1.480 \\
\hline
\end{tabular}

Note. Data in italics represent factors that group together.

value with data from recruitment coordinators. Results of this analysis are shown in Table 2. Although it is difficult to determine an appropriate baseline value (i.e., some students may not have been exposed to practices used by the organization), it is interesting to note that all nine correlations were significant. Moreover, greater convergence in student organization ratings occurred for more visible activities such as the use of job postings or advertisements. Taken together, these data suggest that students rated actual recruitment-related practices used by each organization rather than relying on preconceived notions of what practices might have been used.

\section{Measures of Employer Brand Image and Decisions}

The first survey also collected data on two mediating variables (attitudes toward the organization and perceived job attributes) and one outcome (application intentions). In addition, we obtained data on students' actual application decisions two months after the first survey.

Attitudes. This four-item measure was adapted from the scale used by Harris and Fink (1987). A sample item from the scale is "I have a very favorable impression of this company" $(1=$ strongly disagree; $5=$ strongly agree; $\alpha=.86$ ).

Perceived attributes. Prior recruitment research has measured job seekers' perceptions of large numbers of job attributes (e.g., Harris \& Fink, 1987; Powell, 1991). Because job seekers are unlikely to have knowledge of many attributes prior to their applications, we identified in conversations with career services directors 10 attributes about which potential applicants might have some rudimentary knowledge: salary/wage, location, advancement opportunities, opportunities to learn new skills, availability of excellent training programs, good corporate culture, company reputation, interesting work, benefits, and job security. Respondents rated how likely it was $(1=$ not very likely; $5=$ extremely likely $)$ that each organization they had identified possessed the attribute in question $(\alpha=.79)$.

Application intentions. The two-item application intentions to apply measure was adapted from one used by Taylor and Bergmann (1987). A sample item from the current scale is "I intend to apply for a position with this organization" ( $1=$ strongly disagree $; 5=$ strongly agree $; \alpha=.92)$.

Application decisions. Respondents' actual application decisions were assessed in a second survey distributed two months after the first survey. For each organization they had listed on the first survey, respondents indicated whether or not they had applied for an opening. Second round surveys were returned by 83 of the original participants for a response rate of $62 \%$. Analyses revealed no significant differences in gender, $\chi^{2}(1, N=$ $131)=0.10, n s ;$ GPA, $t(131)=1.23, n s$; years of work experience, $t(131)=0.98, n s$; exposure to recruitment-related practices: publicity, $t(131)=1.75, n s ;$ sponsorships, $t(131)=0.54, n s ;$ word-of-mouth endorsements, $t(131)=0.42, n s$; advertising, $t(131)=1.60, n s$; attitudes, $t(131)=1.25, n s ;$ perceived attributes, $t(131)=0.66, n s ;$ or application intentions, $t(131)=0.64, n s$, of those who did and those who did not respond. 
Table 2

Correspondence Between Students' and Organizations' Perceptions of Recruitment Practices

\begin{tabular}{|c|c|c|}
\hline $\begin{array}{l}\text { Student survey item } \\
\qquad(N=133)\end{array}$ & $\begin{array}{l}\text { Recruitment coordinator item } \\
\qquad(N=29)\end{array}$ & $\begin{array}{l}\text { Correlation } \\
\text { coefficient }\end{array}$ \\
\hline \multicolumn{3}{|c|}{ Sponsorship activities } \\
\hline $\begin{array}{l}\text { I have worked on equipment or products } \\
\text { donated by this organization. }\end{array}$ & $\begin{array}{l}\text { My company donates equipment used by } \\
\text { college students. }\end{array}$ & $.622 * *$ \\
\hline $\begin{array}{l}\text { This organization sponsors scholarships at my } \\
\text { university. }\end{array}$ & $\begin{array}{l}\text { My company provides financial donations for } \\
\text { student scholarships. }\end{array}$ & $.569 *$ \\
\hline $\begin{array}{l}\text { This organization has sponsored events (e.g., } \\
\text { speakers, concerts, sports, events) on } \\
\text { campus }\end{array}$ & $\begin{array}{l}\text { My company sponsors campus events (e.g., } \\
\text { tailgate parties, sporting events). }\end{array}$ & $.572 *$ \\
\hline
\end{tabular}

Word-of-mouth endorsements

Students who have gone to work for this organization have had good experiences.

The engineering faculty think this is a good

This organization has a good relationship with the career services office. place to go to work.
My company uses alumni to recruit students at their alma maters.

To what extent does your college relations unit spend time getting to know engineering faculty? $(1=$ not at all, $5=$ to a great extent)

To what extent does your college relations unit spend time getting to know career services personnel? $(1=$ not at all, $5=$ to a great extent)
$.611^{*}$

$.493 *$

$.522 *$

Advertising

We advertise in students newspapers or flyers or campus

have seen advertising for jobs at this organization in the school newspaper or on flyers.

This organization's recruiting brochures caught my attention.

Job postings gave me detailed information about openings for which this organization is recruiting.
We distribute eye-catching brochures at campus career services centers.

We use job postings in the career services office to provide information about company benefits and hiring.

Note. All items used response scales ranging from 1 (strongly disagree) to 5 (strongly agree). Except where indicated, all items used a dichotomous response scale $(1=n o, 2=y e s)$.

$* p<.05$. ** $p<.01$.

\section{Results}

Because we used a within-subjects design, respondents answered identical questions for up to 10 different organizations (number of organizations: $M=7.02, S D=1.42$ ). The resulting information was arranged into a panel data set with repeated observations for each respondent. Table 3 presents the means, standard deviations, and correlations for 933 observations aggregated to the respondent level for all major study variables.

Greene (1997) argued that the appropriate analytic method to evaluate panel data is fixed-effects regression, which controls for the natural covariation between measures of different observations within each respondent. Fixed-effects regression allowed us to test our hypotheses while partialling out individual differences with dummy coding. Although we calculated separate person effects for the 133 respondents, it should be noted that we conserved space by not reporting these values in our tabled results. Because the decision to apply is a dichotomous variable, we used fixed-effects probit analysis to test hypotheses pertaining to application decisions.

\section{Hypotheses 1-4: Recruitment-Related Practices and Employer Brand Image}

Hypothesis 1 predicted a positive relationship between publicity and attitudes toward the organization. As shown in Tables 4 and 5, publicity was significantly related to attitudes, $\mathrm{B}$ value $=.11$, $t(128)=2.31, p<.01$, but was not significantly related to perceived attributes, $\mathrm{B}$ value $=.06, t(128)=1.71, n s$. Following Cohen and Cohen (1983), we found that the B value for the relationship between publicity and attitudes was significantly greater than that between publicity and perceived attributes, $t(128)=2.498, p<.01$. Thus, Hypothesis 1 was supported. Publicity showed stronger relationships with job seekers' attitudes than it did with their beliefs about specific attributes.

Hypothesis 2 predicted a positive relationship between sponsorship activities and attitudes. As shown in Tables 4 and 5 sponsorship activities were not significantly related to attitudes, $\mathrm{B}$ value $=$ $.01, t(128)=0.24, n s$, or to perceived attributes, $\mathrm{B}$ value $=-.02$, $t(128)=-1.31, n s$. Furthermore, we did not find a significant difference in the $\mathrm{B}$ values of the two relationships, $t(128)=1.122$, 
Table 3

Means, Standard Deviations, Alphas, and Intercorrelations of Study Variables

\begin{tabular}{|c|c|c|c|c|c|c|c|c|c|c|}
\hline Variable & $M$ & $S D$ & 1 & 2 & 3 & 4 & 5 & 6 & 7 & 8 \\
\hline 1. Actual application decisions ${ }^{\mathrm{a}}$ & 1.67 & 0.48 & - & & & & & & & \\
\hline 2. Application intentions & 3.92 & 0.91 & $.596^{* *}$ & $(.918)$ & & & & & & \\
\hline 3. Attitudes & 4.08 & 0.71 & $.407 * *$ & $.496^{* *} *$ & $(.861)$ & & & & & \\
\hline 4. Perceived attributes & 3.89 & 0.80 & $.283^{* *}$ & $.440 * *$ & $.529 * *$ & $(.792)$ & & & & \\
\hline 5. Publicity & 3.41 & 0.96 & .126 & $.199 * *$ & $.297 * *$ & $.240 * *$ & $(.746)$ & & & \\
\hline 6. Sponsorship & 2.66 & 0.89 & .041 & $.163^{*}$ & .121 & $.173 * *$ & $.302 * *$ & $(.699)$ & & \\
\hline 7. Word-of-mouth endorsements & 3.58 & 0.86 & $.216^{* *}$ & $.282^{* * *}$ & $.469 * *$ & $.402^{* *}$ & $.394 * *$ & $.349 * *$ & $(.762)$ & \\
\hline 8. Advertising & 3.35 & 0.77 & $.232 * *$ & $.241^{*}$ & $.332 * *$ & $.292 * *$ & $.166^{* *}$ & $.231 * *$ & $.337 * *$ & $(.778)$ \\
\hline
\end{tabular}

Note. $\quad N=133$. Alpha reliabilities are shown in parentheses along the diagonal. For all scaled measures, $1=$ low and $5=$ high

${ }^{a}$ Means and correlations for application decisions $(1=n o, 2=$ yes $)$ only are based on $n=83$.

$* p<.05$. *** $p<.01$.

$n s$. Thus, Hypothesis 2 was not supported: Sponsorship was not associated with either job seekers' attitudes or their perceptions about specific attributes.

Hypotheses 3 and 4 predicted positive relationships between word-of-mouth endorsements and recruitment advertising, attitudes, and perceived attributes, respectively As shown in Tables 4 and 5, word-of-mouth endorsements were significantly related to both attitudes, $\mathrm{B}$ value $=.33, t(128)=9.52, p<.001$, and perceived attributes, $\mathrm{B}$ value $=.32, t(128)=11.76, p<.01$. Recruitment advertising was also significantly related to both attitudes, $\mathrm{B}$ value $=.24, t(128)=3.69, p<.01$, and perceived attributes, $\mathrm{B}$ value $=.27, t(128)=7.69, p<.01$. Thus, Hypotheses 3 and 4 were both supported, suggesting that for both marketing and recruitment, word-of-mouth endorsements and advertising are positively related to attitudes and perceived job attributes.

\section{Hypothesis 5: Interactive Effects of Recruitment-Related Practices on Brand Image}

Hypothesis 5 predicted that job seekers' attitudes and perceived attributes will be most positive when individuals are exposed to more early recruitment-related practices. Marketing literature suggests that when consumers are exposed to a greater variety of marketing efforts brand image is improved. As we had no a priori reason to examine any particular collection of practices, we examined the two-, three-, and four-way recruitment practice interactions for evidence that exposure to more practices is linked with more positive attitudes and perceived job attributes.

Because of the large number of tests run to explore each interaction and our small sample size, there is a greater risk of making a Type I error (Cohen \& Cohen, 1983). One way to control for this problem is to follow the Fisher protected $t$ method (Darlington,

Table 4

Regression Results for Recruitment-Related Practices and Attitudes

\begin{tabular}{|c|c|c|c|}
\hline Step and variable & Model $\Delta R^{2}$ & B & $t$ \\
\hline 1 Publicity & $.19 * *$ & $.113^{* *}$ & 2.31 \\
\hline Sponsorship activities & & .011 & 0.24 \\
\hline Word-of-mouth endorsements & & $.334 * *$ & 9.52 \\
\hline Advertising & & $.241 * *$ & 3.69 \\
\hline \multicolumn{4}{|l|}{2 Two-way interactions } \\
\hline Publicity $\times$ Sponsorship & $.04 *$ & $.061 * *$ & 2.52 \\
\hline Publicity $\times$ Word-of-Mouth & $.03 *$ & $.058 * *$ & 2.39 \\
\hline Publicity $\times$ Advertising & .01 & .017 & 0.71 \\
\hline Sponsorship $\times$ Word-of-Mouth & .00 & .007 & 0.19 \\
\hline Sponsorship $\times$ Advertising & .01 & .025 & 0.81 \\
\hline Word-of-Mouth $\times$ Advertising & .01 & .024 & 0.61 \\
\hline \multicolumn{4}{|l|}{3 Three-way interactions } \\
\hline Publicity $\times$ Sponsorship $\times$ Word-of-Mouth & $.04 *$ & $.006 * *$ & 2.46 \\
\hline Publicity $\times$ Sponsorship $\times$ Advertising & $.04 *$ & $.007 * *$ & 2.69 \\
\hline Publicity $\times$ Word-of-Mouth $\times$ Advertising & $.03 *$ & $.005^{*}$ & 1.98 \\
\hline Sponsorship $\times$ Word-of-Mouth $\times$ Advertising & .00 & .002 & 0.46 \\
\hline \multicolumn{4}{|l|}{4 Four-way interaction } \\
\hline Publicity $\times$ Sponsorship $\times$ Word-of-Mouth $\times$ Advertising & $.05^{*}$ & $.002 * *$ & 2.56 \\
\hline
\end{tabular}

Note. For within-subjects regression, $N=133$. Because of issues with multicollinearity, each interaction was run as a separate regression. Model $R^{2}$ includes only the effects for the independent variables; person effects are not included. Likewise, the B values for each individual person are not listed because of space constraints. $* p<.05 . \quad * * p<.01$ 
Table 5

Regression Results for Recruitment-Related Practices and Perceived Attributes

\begin{tabular}{lccr}
\hline \multicolumn{1}{c}{ Step and variable } & Model $\Delta R^{2}$ & $\mathrm{~B}$ & \multicolumn{1}{c}{$t$} \\
\hline 1 Publicity & $.20^{* *}$ & .06 & 1.71 \\
Sponsorship activities & & -.02 & -1.11 \\
Word-of-mouth endorsements & & $.32^{* *}$ & 11.76 \\
Advertising & & $.27^{* *}$ & 7.69 \\
2 Two-way interactions & $.05^{*}$ & $.072^{* *}$ & 2.88 \\
Publicity $\times$ Sponsorship & $.03^{*}$ & $.048^{*}$ & 2.08 \\
Publicity $\times$ Word-of-Mouth & $.03^{*}$ & $.052^{*}$ & 2.17 \\
Publicity $\times$ Advertising & .00 & .018 & 0.85 \\
Sponsorship $\times$ Word-of-Mouth & .00 & .014 & 0.82 \\
Sponsorship $\times$ Advertising & .00 & .009 & 0.37 \\
Word-of-Mouth $\times$ Advertising & & & \\
3 Three-way interactions & $.04^{*}$ & $.006^{* *}$ & 2.42 \\
Publicity $\times$ Sponsorship $\times$ Word-of-Mouth & $.04^{*}$ & $.005^{*}$ & 2.04 \\
Publicity $\times$ Sponsorship $\times$ Advertising & $.05^{*}$ & $.009^{* *}$ & 2.92 \\
Publicity $\times$ Word-of-Mouth $\times$ Advertising & .00 & .002 & 0.42 \\
Sponsorship $\times$ Word-of-Mouth $\times$ Advertising & & & \\
Four-way interaction & $.05^{*}$ & $.003^{* *}$ & 2.93 \\
Publicity $\times$ Sponsorship $\times$ Word-of-Mouth $\times$ & & & \\
$\quad$ Advertising & &
\end{tabular}

Note. For within-subjects regression, $N=133$. Because of issues with multicollinearity, each interaction was run as a separate regression. Model $R^{2}$ includes only the effects for the independent variables; person effects are not included. Likewise, the B values for each individual person are not listed because of space constraints. $* p<.05$. ** $p<.01$.

1990). This approach suggests that if the $F$ for the overall regression equation is significant, then the $t$ values for each of the individual predictors within that regression can be examined without concern for Type I error. As shown in Tables 4 and 5, the $F$ value for change in $R_{2}$ for the interaction step is significant for each of the significant interaction regressions. Following the Fisher protected $t$ method, it does not seem likely that the significant interactions are the result of a Type I error. A second and more conservative approach would be to follow the Bonferroni method. Following this method, a more stringent alpha value based on the total number of tests run is used to test the significance of individual predictors (Cohen \& Cohen, 1983; Darlington, 1990). Because we are testing the effects of eleven interactions on each dimension of brand image, we will use a significance level of .01 to determine the significance following the Bonferroni method.

As shown in Tables 4 and 5, we found that the four-way interaction term - an omnibus test of our interaction hypothesiswas significantly related to both attitudes following both methods discussed earlier, $\mathrm{B}$ value $=.002, t(127)=2.56, p<.01$, and perceived attributes, $\mathrm{B}$ value $=.003, t(127)=2.93, p<.01$. Following the Fisher protected $t$ method, we also found that all but one of the two- and three-way interactions which included publicity were significantly related to both attitudes and perceived attributes. When we followed the more conservative Bonferroni method, only 8 of the 12 interactions involving publicity were significant. As shown in Figure 1. we found that increased exposure to both publicity and sponsorship led to the most positive perceptions of attitudes. Plots of the other significant two-way interactions predicting both attitudes and perceived attributes were similar, suggesting that perceptions of brand image are most positive when job seekers have greater exposure to both publicity and other early recruitment-related activities. None of the remaining interactions (i.e., those that did not include publicity) were significantly related to the dimensions of brand image. Given that many interactions were significant, including the four-way interaction, we regarded these findings as partially supporting Hypothesis 5.

\section{Hypotheses 6: Mediation of Recruitment-Related Practice Effects on Decisions}

Hypothesis 6 predicted that employer brand image (i.e., attitudes and perceived attributes) would mediate the relationship between recruitment-related practices and job seekers' decisions to apply.

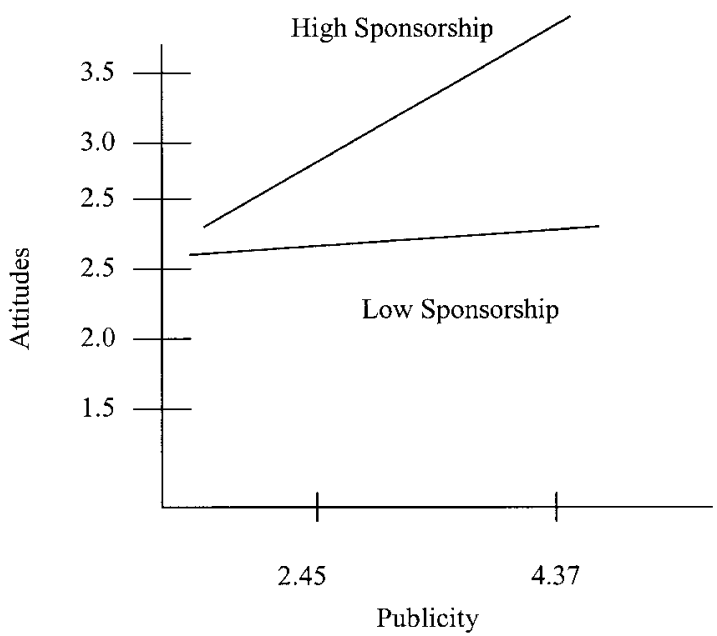

Figure 1. Plot of two-way interaction between publicity and sponsorship attitudes. 
To test this hypothesis, we followed the three-step procedure advocated by Baron and Kenny (1986), and we used both the Time 1 measure of application intentions to apply and the Time 2 measure of actual applications as dependent measures.

To test for mediation, we first established the significant relationships between our independent variables (i.e., the four recruitment-related practices) and the mediators (attitudes and perceived attributes). As discussed in the findings for Hypotheses 1-4, we found significant relationships between three of the recruitment-related practices (publicity, word-of-mouth endorsements, and advertising) and both attitudes and perceived attributes. Next we examined whether our independent variables were related to the dependent variable by regressing the recruitment-related practices on both application intentions and decisions. As shown in Step 1 of Table 6, publicity, B value $=.16, t(128)=2.42, p<.01$; word-of-mouth endorsements, B value $=.24, t(128)=6.44, p<$ .01 ; and advertising, $B$ value $=.19, t(128)=2.59, p<.01$, were significantly related to intentions to apply. As shown in Step 1 of Table 7, word-of-mouth endorsements, $\chi^{2}(78, N=78)=5.40, p$ $<.05$, and advertising, $\chi_{2}(78, N=78)=4.63, p<.05$ were significantly related to application decisions.

In the third step, we found that the two mediators were significantly related to both intentions and application decisions. As shown in Step 2 of Table 6, both attitudes, B value $=.64$, $t(126)=12.11, p<.01$, and perceived attributes, B value $=.36$, $t(126)=5.99, p<.01$, were significantly related to intentions. As shown in Step 2 of Table 7, both attitudes, $\chi^{2}(76, N=76)=$ $32.41, p<.01$, and perceived attributes, $\chi^{2}(76, N=76)=19.86$, $p<.01$, were significantly related to application decisions. Finally, we found that the inclusion of the mediators eliminated the previously significant effects of the recruitment-related practices on both application intentions and decisions. These results supported the mediating effects of brand image on the relationships between recruitment-related practices and both application intentions and decisions.

Table 6

Regression Analyses Predicting Intentions to Apply

\begin{tabular}{lcrr}
\hline \multicolumn{1}{c}{ Equation and predictor } & Model $R^{2}$ & $\mathrm{~B}$ & \multicolumn{1}{c}{$t$} \\
\hline & $.14^{* *}$ & & \\
& & $.16^{* *}$ & 2.42 \\
Publicity & -.05 & -.63 \\
Sponsorship & $.24 * *$ & 6.44 \\
Word-of-mouth endorsements & $.19^{* *}$ & 2.59 \\
Advertising & $.36^{* *}$ & & \\
& & -.03 & -.44 \\
Publicity & -.04 & -.56 \\
Sponsorship & .13 & 1.82 \\
Word-of-mouth endorsements & -.01 & -0.39 \\
Advertising & $.64^{* *}$ & 12.11 \\
Attitudes & $.36^{* *}$ & 5.99 \\
Perceived attributes & &
\end{tabular}

Note. For within-subjects regression, $N=133$. Model $R^{2}$ includes only the effects for the independent variables; person effects are not included. Likewise, the B values for each individual person are not listed because of space constraints.

$* p<.05$. ** $p<.01$.
Table 7

Probit Analysis for Job Seekers' Application Decisions

\begin{tabular}{clll}
\hline Equation & \multicolumn{1}{c}{ Variable } & Estimate & $\chi^{2}$ \\
\hline \multirow{2}{*}{1} & Publicity & .082 & 0.87 \\
& Sponsorship & .022 & 0.09 \\
& Word-of-mouth endorsements & $.282^{*}$ & 5.40 \\
\multirow{4}{*}{2} & Advertising & $.234^{*}$ & 4.63 \\
& Publicity & .010 & 0.02 \\
& Sponsorship & .017 & 0.07 \\
& Word-of-mouth endorsements & .124 & 1.09 \\
& Advertising & .074 & 0.63 \\
& Attitudes & $.649^{* *}$ & 32.41 \\
& Perceived attributes & $.432^{* *}$ & 19.86 \\
\hline
\end{tabular}

Note. For within-subjects probit analysis, $N=83$.

$* p<.05$. ** $p<.01$.

\section{Discussion}

Our findings suggest that the literature on customer-based brand equity may be equally potent for understanding application decisions of highly skilled but inexperienced job seekers in a tight labor market. First, the literature on customer-based brand equity was useful in identifying four different sets of early recruitmentrelated activities that should be related, theoretically, to two dimensions of employer brand image, attitudes and perceived attributes. Second, we found support for a mediation model in which early recruitment-related practices affected application decisions through their impact on employer brand image dimensions. Finally, while three of the early recruitment-related practices had direct effects on employer brand image, our results suggested that early recruitment-related practices may have their greatest effects when companies use them in conjunction with one another.

As suggested in the literature on customer-based brand equity, organizations seem to be able to create an overall positive feeling toward the company and its job opportunities through publicity. However, this generalized form of communication does not appear to be an effective tool for influencing potential applicants' beliefs about specific attributes of job opportunities. More importantly, the interaction terms which included publicity were the only ones that were significantly related to attitudes and perceived attributes. This suggests that firms which are able to create publicity about themselves may receive the greatest return for their investment in other early recruitment activities. It is possible that publicity, because it is perceived as coming from a source other than the company (e.g., a newspaper or periodical reporter), provides legitimacy to other forms of recruitment. In other words, student applicants may be more willing to believe the information that they receive from other sources when they have also been more exposed to the company through news reports or articles.

Disappointingly, given the increased spending on sponsorship activities by organizations, our findings suggested that sponsorship was not an effective tool for affecting employer brand image. Sponsorship did not have a significant effect on attitudes or perceived attributes, and it did not seem to increase the impact of other recruitment-related practices (interactions with sponsorship were only significant when publicity was also part of the interaction term). Potentially, the impact of sponsorship is so weak 
because either fewer companies than estimated use sponsorship as a recruitment tool or too few of the respondents were aware of sponsorship efforts (note that the mean for sponsorship was significantly lower than the means for the other three early recruitment practices). These findings suggest that firms may need to create more awareness of their sponsorship actions, especially through publicity, if they are to reap the benefits of these activities.

Advertising was significantly related to students' perceptions about the attributes of the company and the job opportunity. This finding suggests that firms can be proactive in helping students form positive impressions about specific attributes by making information readily available through job postings, Web sites, etc. Advertising was also significantly related to respondents' attitudes toward the company. However, it is not clear from the data how advertising may affect these general perceptions. This form of early recruitment activity may affect attitudes directly, through content that communicates a general positive message, or indirectly, by either increasing awareness of the company (Keller, 1993) or providing specific information about attributes (Barber \& Roehling, 1993). Future research should examine the effect of advertising on attitudes so that firms can be more calculated when they present information for the purpose of recruitment.

Our findings suggest that early in the job search potential applicants may rely most heavily on information and appraisals from other people to evaluate job opportunities. Although our study demonstrates the relationship between exposure to positive word-of-mouth endorsements and prospective applicants' decisions, we did not examine either the valence or accuracy of information obtained from such sources. Given the potency of the relationship between word-of-mouth endorsements and both attitudes and perceived attributes, additional research should explore the processes through which recruitment information is acquired and disseminated by individuals who act as sources of information. From a practical standpoint, our results indicate that expanding and capitalizing on word-of-mouth endorsements would provide a highly effective and economical method for increasing applicant pools.

Our results provide some support for the interactions suggested in brand equity literature, that is, the presence of multiple components of the recruitment mix seem to send a positive signal about the company, thereby creating positive general feelings toward job opportunities and positive perceptions about the presence of specific attributes. However, we were surprised that more of the interactions were not significant, especially those that included word-of-mouth and advertising. It is possible that inexperienced job seekers may not pay attention to direct forms of recruitment unless they are already familiar with the company based on some other form of exposure. Therefore, future research should examine whether other types of general organizational practices that increase awareness of the company (e.g., product advertising) similarly increase applicants' attenuation to more traditional forms of recruitment.

\section{Study Limitations}

Several limitations constrain the generalizability of our interpretations and findings. First, despite attempts to network with career services staff and use of a lottery incentive (respondents could win up to $\$ 100$ for returning completed surveys), our return rate was disappointingly low. However, available data indicate that our sample did not deviate demographically from larger populations of engineering graduates. Future studies that assess refusal to participate or population variables that might affect generalizability would enable researchers to estimate how serious this problem is.

A second concern is that our measures of organizational recruitment activities only assess exposure to positive information. Thus, we are not able to assess how exposure to negative or neutral information might affect potential applicants' perceptions of employment brand image. Customer brand equity literature suggests that exposure to negative information will lead to negative brand perceptions (Aaker, 1991; Keller, 1993), and recruitment research suggests that individuals might discount organizations when exposed to neutral information (Stevens, Dragoni, \& Collins, 2001). However, future research should explore how perceptions of employment brands may differ based on the type of information to which the potential applicants are exposed.

Third, our procedures examined the relationships between recruitment, brand image, and brand equity only for firms which were part of the decision sets of respondents. Although this is the set of companies for which employment brand image should have the greatest effect, we could not determine the extent to which brand image helps individuals develop their final decision sets. Future research should examine other dimensions of customer brand equity that have been shown to be related to decision making, such as familiarity or perceived quality (Keller, 1993). For example, future research should ask respondents to evaluate both familiar and unfamiliar firms to test for the effects of recognition.

A fourth limitation is that common method variance may explain some of the observed relationships. However, the use of the within-subjects design did enable us to partial out some common method variance. If our findings were largely attributable to common methods, we would expect the predictor criterion covariance to be consistent across all of the organizations rated by each respondent. As a result, the person variable in the fixed-effects regression models would have explained nearly all of the variance in the outcomes. Yet, this was not the case; most predictors were significant even after controlling for person effects. Thus, it seems unlikely that the pattern of results can be explained by common method variance.

A more serious concern given our cross-sectional data collection is that it was not possible to determine the direction of causality for the relationships between recruitment practices, cognitions and affective reactions, and intentions. Because these data were collected at the same time, we cannot rule out the possibility of reverse causality. For example, it is possible that organizational attraction may have prompted potential applicants to seek exposure to more recruitment practices. However, we did find similar patterns of results between-our-predictors and the decision to apply, which was collected 2 months later. The use of controlled lab or field studies would help in establishing the causal impact of early and later recruitment-related practices and test the effects of other factors theoretically linked to brand equity. 


\section{Conclusion}

Overall, our results suggest that highly skilled job seekers in a tight labor market behave similarly to consumers in a crowded marketplace. Brand equity researchers have found that firms can use their marketing mix to affect the brand image that consumers hold toward their products and that this image in turn affects customer-based brand equity. Similarly, we found that exposure to early recruitment activities was positively related to job seekers' attitudes and perceived attributes. Further, these elements of brand image were significantly related to application intentions and actual decisions. Note that the regression model containing the four early recruitment activities, attitudes, and perceived attributes explained about $36 \%$ of the variance in intentions, suggesting that we captured many of the key factors in job seekers' decision processes.

From a practical standpoint, the findings suggest that engineering students' may be more likely to apply to an organization when they have been exposed to early recruitment-related activities. Thus, firms that understand how their job opportunities match the needs of employees and can communicate the value of their job opportunities through a strong and consistent employment brand will have a strategic advantage in the competition for talent. Investments in recruitment activities such as publicity, word-ofmouth endorsements, and advertising may be particularly beneficial for high technology firms, because their success and survival depend on being able to attract the knowledge workers who develop new products and services. Advantages in attracting applicants may translate into strategic advantages in the capacity to generate and maintain new business. Furthermore, since the findings mirror those found in the marketing literature, staffing managers and recruiters may wish to work more closely with marketing experts or become more familiar with marketing concepts to ensure that they are creating a positive and unique brand image in the minds of potential applicants.

\section{References}

Aaker, D. A. (1991). Managing brand equity: Capitalizing on the value of a brand name. New York: The Free Press.

Aaker, D. A. (1996). Building strong brands. New York: The Free Press.

Aaker, D. A., \& Biel, A. L. (1993). Brand equity and advertising. Hillsdale, NJ: Erlbaum.

Alderfer, C. P., \& McCord, C. G. (1970). Personal and situational factors in the recruitment interview. Journal of Applied Psychology, 54, 377385.

Anderson, J. R. (1983). The architecture of cognition. Cambridge, MA: Harvard University Press.

Barber, A. E. (1998). Recruiting employees: Individual and organizational perspectives. Thousand Oaks, CA: Sage.

Barber, A. E., \& Roehling, M. V. (1993). Job postings and the decision to interview: A verbal protocol analysis. Journal of Applied Psychology, 78, 845-856.

Baron, R. M., \& Kenny, D. A. (1986). The moderator-mediator variable distinction in social psychological research: Conceptual, strategic, and statistical considerations. Journal of Personality and Social Psychology, 51, 1173-1182.

Behr, P. (1997, December). Tech boom, Help wanted: The scramble to fill the void. The Washington Post, A1.

Belt, J. A., \& Paolillo, J. G. P. (1982). The influence of corporate image and specificity of candidate qualifications on response to recruitment advertisement. Journal of Management, 8, 105-112.

Bliese, P. D. (1998). Group size, ICC values, and group-level correlations: A simulation. Organizational Research Methods, 1, 355-373.

Boudreau, J. W., \& Rynes, S. L. (1985). Role of recruitment in staffing utility analysis. Journal of Applied Psychology, 70, 354-366.

Boulding, W., \& Kirmani, A. (1993). A consumer-side experimental examination of signaling theory: Do consumers perceive warranties as signals of quality? Journal of Consumer Research, 20, 111-123.

Boulding, W., Lee, E., \& Staelin, R. (1994). Mastering the mix: Do advertising, promotion, and salesforce activities lead to differentiation? Journal of Marketing Research, 31, 159-172.

Breaugh, J. A., \& Starke, M. (2000). Research on employee recruitment: So many studies, so many remaining questions. Journal of Management, 26, 405-434.

Cable, D. M., \& Turban, D. B. (2001). Establishing the dimensions, sources, and value of job seekers' employer knowledge during recruitment. Unpublished manuscript.

Cameron, G. (1994). Does publicity outperform advertising: An experimental test of the third-party endorsement. Journal of Public Relations Research, 6, 185-207.

Cobb-Walgren, C. J., Ruble, C. A., \& Donthu, N. (1995). Brand equity, brand preference, and purchase intent. Journal of Advertising, 3, 25-40.

Cohen, J., \& Cohen P. (1983). Applied multiple regression/correlation analysis for the behavioral sciences. Hillsdale, NJ: Erlbaum.

Coombs, G., \& Rosse, J. G. (1992). Recruiting and hiring the hightechnology professional: Trends and future directions. Advances in Global High-Technology Management, 1, 91-107.

Darlington, R. B. (1990). Regression and linear models. New York: McGraw Hill.

Dohm, A. (2000). Gauging the labor force effects of retiring babyboomers. Monthly Labor Review, 123(7), 17-25.

Fisher, C. D., Ilgen, D. R., \& Hoyer, W. D. (1979). Source credibility, information favorability, and job offer acceptance. Academy of Management Journal, 22, 94-103.

Gatewood, R. D., Gowan, M. A., \& Lautenschlager, G. J. (1993). Corporate image, recruitment image, and initial job choice decisions. Academy of Management Journal, 36, 414-427.

Greene, W. H. (1997). Econometric analysis. Upper Saddle River, NJ: Prentice Hall.

Hallahan, K. (1996). Product publicity: An orphan of marketing research. In E. Thorson and J. Moore (Eds.), Integrated Communication: Synergy of Persuasive Voices (pp. 305-330). Mahwah, NJ: Erlbaum.

Harris, M. M., \& Fink, L. S. (1987). A field study of applicant reactions to employment opportunities: Does the recruiter make a difference? Personnel Psychology, 40, 765-786.

Heilman, C. M., Bowman, D., \& Wright, G. P. (2000). The evolution of brand preferences and choice behaviors of consumers new to a market. Journal of Marketing Research, 37, 139-155.

Highhouse, S., Zickar, M. J., Thorsteinson, T. J., Stierwalt, S. L., \& Slaughter, J. E. (1999). Assessing company employment image: An example in the fast food industry. Personnel Psychology, 52, 151-172.

Hsee, C. K., Loewenstein, G. F., Blount, S., \& Bazerman, M. H. (1999). Preference reversals between joint and separate evaluations of options: A review and theoretical analysis. Psychological Bulletin, 125, 576590.

Johar, G. V., \& Pham, M. T. (1999). Relatedness, prominence, and constructive sponsor identification. Journal of Marketing Research, 36, 299-312.

Keller, K. L. (1993). Conceptualizing, measuring, and managing customerbased brand equity. Journal of Marketing, 57, 1-30.

Kilduff, M. (1990). The interpersonal structure of decision making: A 
social comparison approach to organizational choice. Organizational Behavior and Human Decision Processes, 47, 270-288.

Koerner, B. I. (1997, March 10). Top schools-No. 1: MIT. U.S. News and World Report, 10, 94-95.

Lumsden, H. H. (1967, February-March). The plant visit: A crucial area of recruiting where candidates are won or lost. Journal of College Placement, 27, 74-76, 78, 80, 84.

Mason, N. A., \& Belt, J. A. (1986). Effectiveness of specificity in recruitment advertising. Journal of Management, 12, 426-432.

May, K. (1998). Work in the 21st century: Recruiting in a tight labor market. The Industrial-Organizational Psychologist (TIP), 36, 39-41.

Milgrom, P., \& Roberts, J. (1986). Price and advertising as signals of product quality. Journal of Political Economy, 55, 10-25.

Munk, N. (1998). The new organization man. Fortune, 137(5), 62-74.

Olian, J. D. (1986). Staffing. In E. A. Locke (Ed.), Generalizing from laboratory to field settings: Research from industrial/organizational psychology, organizational behavior and human resources (pp. 13-42). Lexington, MA: Heath Lexington.

Poe, A. C. (2000, May). Face value: Snag students early by establishing a long-term personal presence on campus. HR Magazine, 45, 60-68.

Powell, G. N. (1991). Applicant reactions to the initial employment interview: Exploring theoretical and methodological issues. Personnel Psychology, 44, 67-83.

Rajaretnam, J. (1994). The long-term effects of sponsorship on corporate and product image: Findings of a unique experiment. Marketing and Research Today, 62-70.

Rossiter, J. R., \& Percy, L. (1987). Advertising and promotion management. New York: McGraw-Hill.

Rynes, S. L. (1991). Recruitment, job choice, and post-hire consequences. In M. D. Dunnette \& L. M. Hough (Eds.), Handbook of industrial and organizational psychology (2nd ed., Vol. 2, pp. 399-444). Palo Alto, CA: Consulting Psychologists Press.

Rynes, S. L., \& Barber, A. E. (1990). Applicant attraction strategies: An organizational perspective. Academy of Management Review, 15, 286310.

Schmitt, N., \& Coyle, B. W. (1976). Applicant decisions in the employment interview. Journal of Applied Psychology, 61, 184-192.

Schwartz, N., Kumpf, M., \& Bussman, W. (1986). Resistance to persuasion as a consequence of influence attempts of advertising and nonadvertising communications. Psychology, A Quarterly Journal of Human Behavior, 23, 72-76.

Simon, C. J., \& Sullivan, M. W. (1993). The measurement and determinants of brand equity: A financial approach. Marketing Science, 12, $28-52$.

Stevens, C. K., Dragoni, L., \& Collins, C. J. (2001, April). Familiarity, organizational images, and perceived fit as antecedents to the application decisions of new graduates. Paper presented at the 2001 Annual Meeting of the Society for Industrial Organizational Psychology, San Diego, CA

Taylor, M. S. S., \& Bergman, T. J. (1987). Organizational recruitment activities and applicants' reactions at different stages in the recruitment process. Personnel Psychology, 40, 261-285.

Turban, D. B., \& Greening, D. W. (1997). Corporate social performance and organizational attractiveness to prospective employees. Academy of Management Journal, 40, 658-672.

United States Department of Labor. (2001). United States Department of Labor, Bureau of Labor Statistics, Report USDL 00-185. Retrieved August 10, 2001, from http://stats/bls.gov.newsrels.htm

Wilke, W. (1986). Consumer behavior. New York: Wiley.

Wyer, R. S., \& Srull, T. K. (1989). Person memory and judgment. Psychological Review, 96, 58-83.

Received September 11, 2001

Revision received March 18, 2002

Accepted March 18, 2002 